\title{
Genotype by Environment Interaction for Grain Yield in Spring Barley Using Additive Main Effects and Multiplicative Interaction Model
}

\author{
K. Nowosad ${ }^{1}$, A. Tratwal ${ }^{2}$ and J. Bocianowski ${ }^{3 *}$ \\ ${ }^{1}$ Department of Genetics, Plant Breeding and Seed Production, Wrocław University of Environmental and \\ Life Sciences, Grunwaldzki 24A, 53-363 Wrocław, Poland \\ ${ }^{2}$ Department of Pests Methods Forecasting and Plant Protection Economy, Institute of Plant Protection - \\ National Research Institute, Władysława Węgorka 20, 60-318 Poznań, Poland \\ ${ }^{3}$ Department of Mathematical and Statistical Methods, Poznań University of Life Sciences, \\ Wojska Polskiego 28, 60-637 Poznań, Poland
}

(Received 12 December 2017; Accepted 6 June 2018; Communicated by E. Khlestkina)

\begin{abstract}
Monoculture and use of disease resistant varieties on large scale usually leads to selection of new pathogen races able to overcome the resistance. The use of variety mixtures can significantly improve the control of the disease and provides stable yield among different environments. The objective of this study was to assess genotype by environment interaction for grain yield in spring barley genotypes grown in two places different in terms of soil and meteorological conditions by the additive main effects and multiplicative interaction model. The study comprised 25 spring barley genotypes (five cultivars: Basza, Blask, Skarb, Rubinek and Antek, and 20, two- and three-component mixtures), analyzed in eight environments (compilations of two locations and four years) through field trials arranged in a randomized complete block design, with three replicates. Grain yield of the tested genotypes varied from 32.88 to $74.31 \mathrm{dt} / \mathrm{ha}$ throughout the eight environments, with an average of $54.69 \mathrm{dt} / \mathrm{ha}$. In the variance analysis, $68.80 \%$ of the total grain yield variation was explained by environment, $6.20 \%$ by differences between genotypes, and $7.76 \%$ by genotype by environment interaction. Grain yield is highly influenced by environmental factors.
\end{abstract}

Keywords: adaptability, biplot, grain yield, spring barley, stability

\section{Introduction}

In Poland, the use of variety mixtures (mainly in barley cultivation) has been widely introduced into agricultural practice. The main concentration has been on species mixtures and spring barley variety mixtures. It is widely recognized that biodiversity can strongly influence ecosystem functioning. One of the idea in the line of increasing biodiversity of cultivated systems can be mixtures of varieties (Barot et al. 2017). Mixed stands are less susceptible to unfavorable environmental conditions, such as weather fluctuations and other abiotic factors as well as more resistant to biotic stress (diseases, pests, weeds). It has been found that crops sown and managed as mixtures operate different epidemiologi-

*Corresponding author; E-mail: jboc@up.poznan.pl; Phone: +48-61-8487143; Fax: +48-61-8487140 
cal and ecological factors, which lead to considerable disease reduction, better pest and weed control, which translate into higher and more stable grain yields when compared to the mixture components grown in pure stands (Finckh et al. 1998; Philips and Wolfe 2005).

Grain yield in spring barley is a very complex quantitative trait, which expression is the result of genotype, environment and the genotype $\times$ environment interaction (GEI). Complexity of this traits is a results different reactions of genotypes on changeable environmental conditions during plant development. The yield trial is one of the most common experiments in agricultural research. It is conducted by testing a number of genotypes in a number of environments. Multi-environment yield trials are commonly conducted to obtain information that supports recommendations of superior genotypes for cultivation. There are two factors included in multi-environment trial, genotypes and environments. Environment can be a set of locations, sites, years, etc. (Paroda and Hayes 1971; Kieloch and Weber 2015; Solonechnyi et al. 2015; Elakhdar et al. 2017).

The GEI is often analyzed by the additive main effects and multiplicative interaction (AMMI) model (Zobel et al. 1988). The AMMI analysis first fits additive effects for host genotypes and environments by the usual additive analysis of variance procedure and then fits multiplicative effects for $\mathrm{G} \times \mathrm{E}$ by principal component analysis - PCA (Gollob 1968; Gabriel 1978). The use of multivariate techniques permits a better use of information than the regression methods in the multi-environment yield trial analysis. The AMMI biplot graphic display simultaneously both main and interaction effects for genotypes and environments, and enables a single analysis of the GEI.

The objective of this study was to assess genotype by environment interaction for grain yield in spring barley grown in two places different in terms of soil and meteorological conditions by the additive main effects and multiplicative interaction model.

\section{Materials and Methods}

Plant material for field trials consisted of five spring barley cultivars: Basza (Ba), Blask (Bl), Skarb (S), Rubinek (R) and Antek (A), ten two-way mixtures (Basza/Blask, Antek/ Basza, Basza/Skarb, Basza/Rubinek, Antek/Blask, Antek/Skarb, Antek/Rubinek, Blask/ Skarb, Blask/Rubinek, Rubinek/Skarb) and ten three-way mixtures (Antek/Basza/Blask, Antek/Blask/Skarb, Antek/Basza/Rubinek, Antek/Blask/Rubinek, Antek/Basza/Skarb, Blask/Rubinek/Skarb, Basza/Blask/Rubinek, Antek/Rubinek/Skarb, Basza/Blask/Skarb, Basza/Rubinek/Skarb) combinations. Sowing norm was 300 grains $\mathrm{m}^{-2}$, and the share of mixture components was 1:1 or 1:1:1 in the case of three-component mixtures.

The study was carried out during two locations differed in terms of soil and weather conditions: Plant Breeding Smolice - IHAR Group Bąków Division, opolskie $\left(50^{\circ} 42^{\prime} \mathrm{N}, 18^{\circ} 28^{\prime} \mathrm{E}\right)$ and Experimental Station for Variety Station, Kościelna Wieś, wielkopolskie province $\left(51^{\circ} 47^{\prime} \mathrm{N}, 1^{\circ} 00^{\prime} \mathrm{E}\right)$ in $2010-2013$ (eight environments). The field trials at all locations were arranged in a randomized complete block design, with three replicates. Each genotype was grown in a four row plot of $10 \mathrm{~m}^{2}$ (Bąków) and $15 \mathrm{~m}^{2}$ 
(Kościelna Wieś). Rows spacing in plots - $12.5 \mathrm{~cm}$, seed drill type - Oyord (Bąków), SPZ 1,5/2 (Kościelna Wieś). The yielding was determined for all plots. After being harvested with a combine harvester the yield from each plot was weighted and converted into $\mathrm{dt} / \mathrm{ha}$. Fertilization - N: 60-60 kg/ha, P: 30-40 kg/ha, K: 50-60 kg/ha. Soil types: podsolic soil and leached brown soil (Bąków); leached brown soil and acid brown soil (Kościelna Wieś). No fungicide treatments were applied in the experiments.

Mature grain was harvested from each plot using combine. Weight of grain from each plot was measured and used to calculate yield in $\mathrm{dt} / \mathrm{ha}$. Three-way analysis of variance (ANOVA) was performed to verify the hypotheses of lack of effects of genotypes, locations and years as well as the hypotheses about a lack of all interactions on the variability of grain yield. Next, a two-way (genotypes, environments: combination of locations and years) fixed effect model was fitted to determine the magnitude of the main effects of variation and their interaction on grain yield. Least-squares means were simultaneously produced for the AMMI model. Genotype main effect $(G)$, environment main effect $(E)$ and genotype by environment (GE) interaction were analyzed by the AMMI model (Gauch and Zobel 1990; Nowosad et al. 2016, 2017), represented by:

$$
y_{g e}=\mu+\alpha_{g}+\beta_{e}+\sum_{n=1}^{N} \lambda_{n} \gamma_{g n} \delta_{e n}+Q_{g e},
$$

in which: $y_{g e}$ is the yield mean of genotype $g$ in environment $e, \mu$ is the grand mean, $\alpha_{g}$ are the genotypic mean deviations (means minus grand mean), $\beta_{e}$ are the environmental mean deviations, $N$ is the number of PCA axis retained in the adjusted model, $\lambda_{n}$ the square root of the eigenvalue of the PCA axis $n, \gamma_{g n}$ is the genotype eigenvector for PCA axis $n, \delta_{e n}$ is the environment eigenvector for PCA axis $n, Q_{g e}$ are the residuals, including AMMI noise and pooled experimental error. Expected distribution of is normal. We used the critical significance level equal to 0.001, resulting from a Bonferroni correction. The AMMI stability value (ASV) was used to compare the stability of genotypes as described by Purchase (1997):

$$
A S V=\sqrt{\left[\frac{S S_{I P C A 1}}{S S_{I P C A 2}}\left(I P C A_{1}\right)\right]^{2}+\left(I P C A_{2}\right)^{2}},
$$

where SS is the sum of squares, IPCA1 and IPCA2 are the first and the second interaction principal component axes, respectively; and the IPCA 1 and IPCA 2 scores were the genotypic scores in the AMMI model. Genotypes with lower ASVs were considered relatively stable. The PCA analysis level of significance was tested with the $F$ test. Contrast analysis was performed to test the difference in grain yield between mixtures and average of their pure cultivars. For the AMMI analysis and contrast analysis, statistical package GenStat v. 17 was used. 


\section{Results}

Results from three-way ANOVA indicated that the main effects of genotype, location and years as well as all interactions were significant for grain yield at the 0.001 level. The results of field trials demonstrated the impact of weather conditions, environment and genotypes on the grain yield of spring barley cultivars, and two- and three-component mixtures. The three sources of variation were highly significant. In the analysis of variance, the sum of squares for environment main effect represented $68.80 \%$ of the total, and this factor had the highest effect on grain yield (Table 1). The differences between genotypes explained $6.20 \%$ of the total yield variation, while the effects of GE interaction explained $7.76 \%$. Values for the three principal components were also highly significant. The three principal components of GE interaction accounted jointly for $82.93 \%$ of the whole effect it had on the variation of grain yield. The first principal component (IPCA 1) accounted for $48.99 \%$ of the variation caused by interaction, while IPCA 2 and IPCA 3 accounted for 22.51 and $11.43 \%$, respectively. The obtained cultivars and mixtures have the best adaptability to the environmental conditions for which they were bred, which explains why $68.80 \%$ of the variation in grain yield data was due to the main effects of locations.

Table 1. Analysis of variance of main effects and interactions for spring barley genotypes grain yield

\begin{tabular}{|l|r|c|c|c|c|}
\hline \multicolumn{1}{|c|}{ Source of variation } & d.f. & Sum of squares & Mean squares & $F$ & $\begin{array}{c}\text { Variability explained } \\
(\%)\end{array}$ \\
\hline Genotypes & 24 & 4569 & 190.4 & $14.53 * * *$ & 6.20 \\
\hline Environments & 7 & 50678 & 7239.7 & $33.70^{* * *}$ & 68.80 \\
\hline Blocks & 24 & 5157 & 214.9 & $16.4 * * *$ & 7.00 \\
\hline GE interaction & 168 & 5714 & 34.0 & $2.60^{* * *}$ & 7.76 \\
IPCA 1 & 30 & 2799 & 93.3 & $7.12^{* * *}$ & 48.99 \\
IPCA 2 & 28 & 1286 & 45.9 & $3.51^{* * *}$ & 22.51 \\
IPCA 3 & 26 & 653 & 25.1 & $1.92 * *$ & 11.43 \\
Residuals & 84 & 975 & 11.6 & 0.89 & \\
\hline Error & 576 & 7546 & 13.1 & & \\
\hline
\end{tabular}

${ }^{* *} p<0.01 ; * * * p<0.001$. IPCA, principal component of interaction.

Grain yield of the tested cultivars, and two- and three-component mixtures varied from 32.88 (for Antek in Bąków 2013) to $74.31 \mathrm{dt} / \mathrm{ha}$ (for Basza in Kościelna Wieś 2012) throughout the eight environments, with an average of $54.69 \mathrm{dt} /$ ha (Table 2). The Rubinek/Skarb mixture had the highest average grain yield (57.80), and the Antek had the lowest (47.89). The average grain yield per location also varied from $38.84 \mathrm{dt} / \mathrm{ha}$, in Bąków 2011, to 65.64 dt/ha in Kościelna Wieś 2012.

Tested genotypes interacted differently with climate and weather conditions in the observed combinations years and locations. The genotypes $\mathrm{A}, \mathrm{A} / \mathrm{Bl}, \mathrm{A} / \mathrm{Ba}, \mathrm{A} / \mathrm{Ba} / \mathrm{Bl}, \mathrm{A} / \mathrm{R}$, $\mathrm{A} / \mathrm{S}, \mathrm{A} / \mathrm{Bl} / \mathrm{S}, \mathrm{A} / \mathrm{Ba} / \mathrm{R}, \mathrm{A} / \mathrm{Bl} / \mathrm{R}$, and $\mathrm{A} / \mathrm{Ba} / \mathrm{S}$ interacted positively with the Bąków 2011, but 


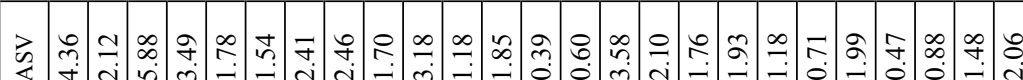

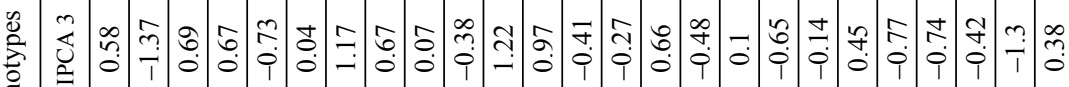

品

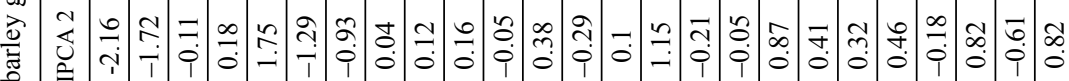

焉

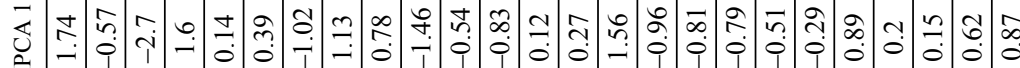

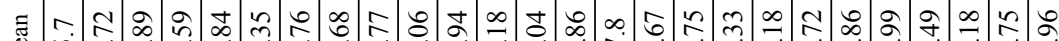

¿ ñ

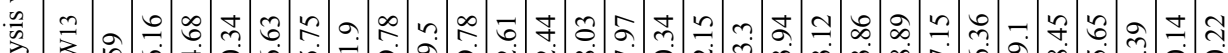

ते

䒕

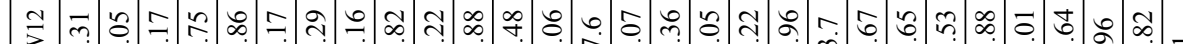

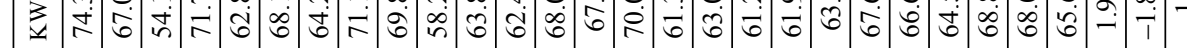

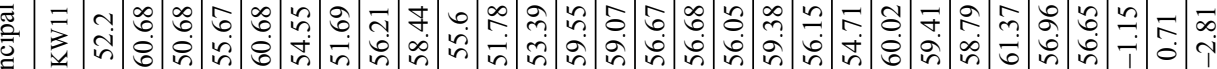

咅

를

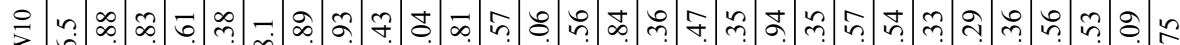

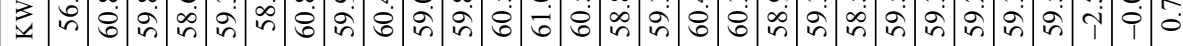

:

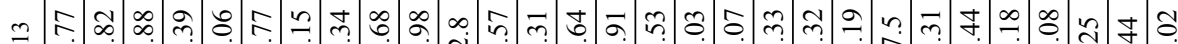

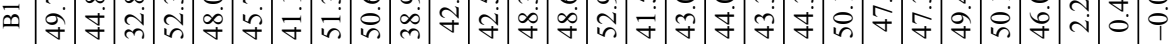

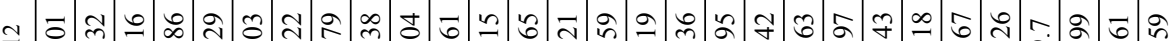
m

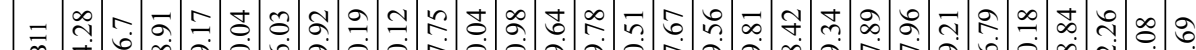

च

苂

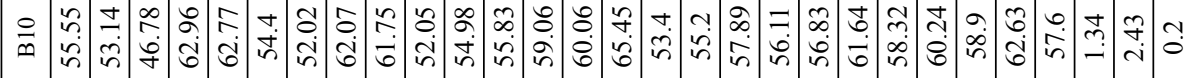
$\stackrel{\oplus}{\frac{0}{2}}$

芴

品

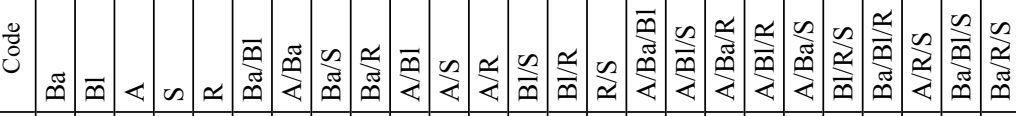

ह

离.

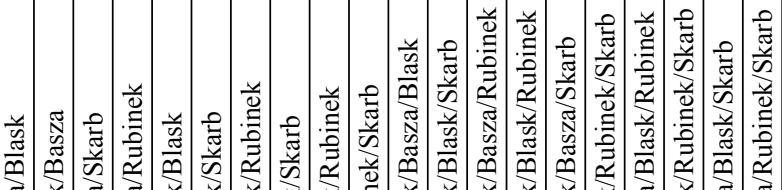

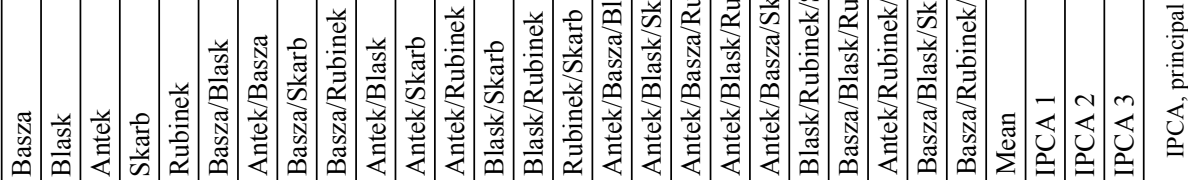




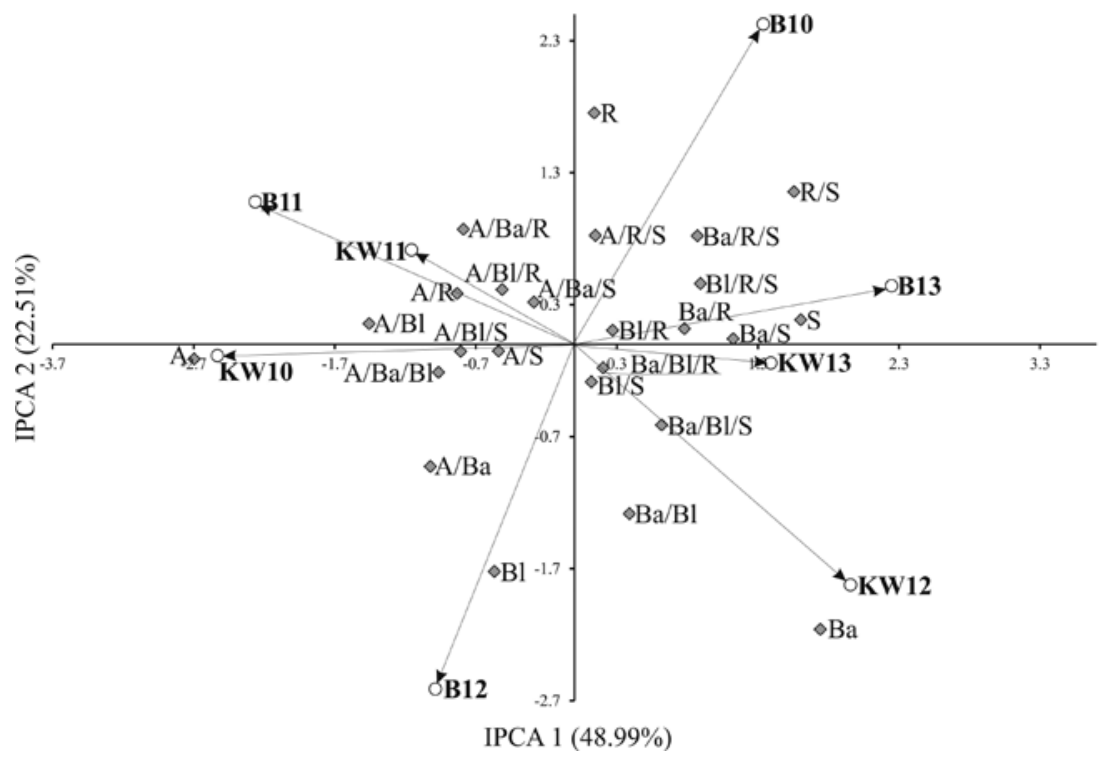

Figure 1. Biplot for genotype by environment interaction of spring barley cultivars, and two- and three-component mixtures in eight environments, showing the effects of primary and secondary components (IPCA 1 and IPCA 2, respectively) [circles not filled color - environments: B - Bąków; KW - Kościelna Wieś in 20102013; rhombs filled color - genotypes, codes see Table 2]
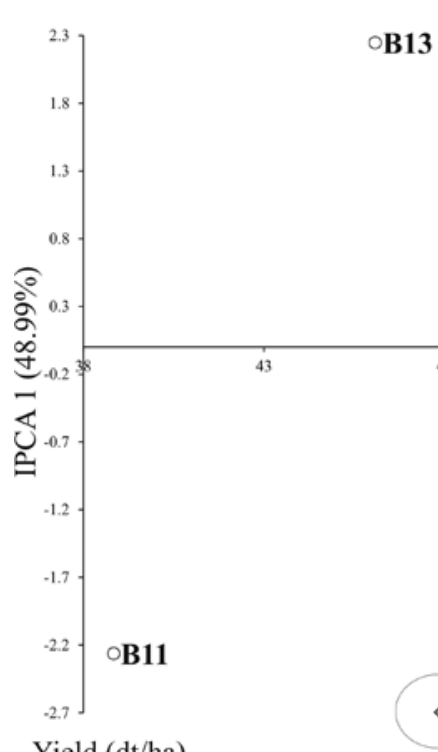

Yield (dt/ha)

Figure 2. Biplot for the primary component of interaction (IPCA 1) and average spring barley grain yield (dt/ ha). Vertical line at the centre of biplot is the general grand mean. [circles not filled color - environments: $\mathbf{B}$ - Bąków; KW - Kościelna Wieś in 2010-2013; rhombs filled color - genotypes, codes see Table 2] 


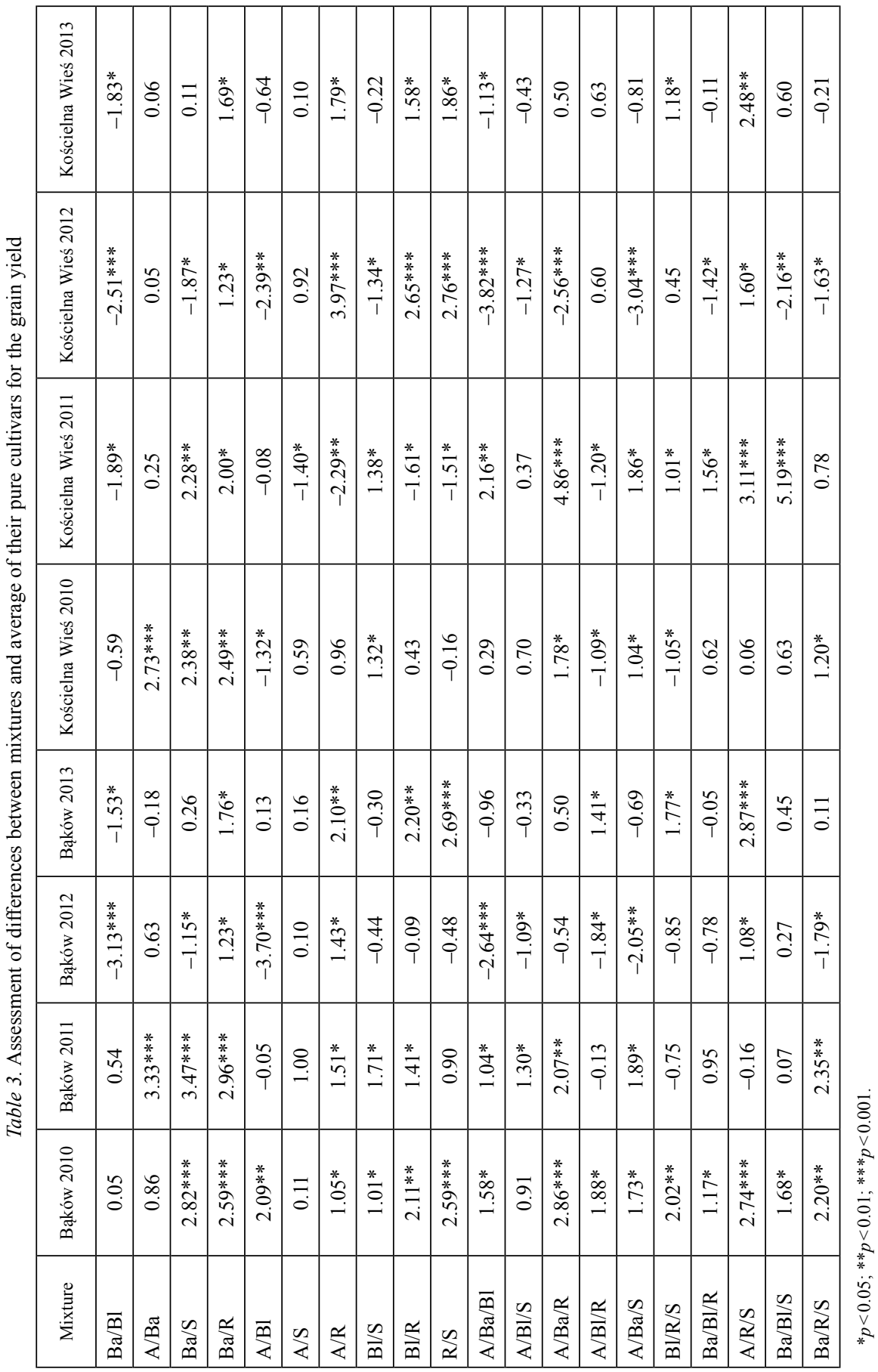


negatively with the Bąków 2013 and Kościelna Wieś 2013 (Figures 1 and 2). The genotypes $\mathrm{Ba}, \mathrm{S}, \mathrm{R} / \mathrm{S}, \mathrm{Ba} / \mathrm{S}, \mathrm{Bl} / \mathrm{R} / \mathrm{S}, \mathrm{Ba} / \mathrm{R} / \mathrm{S} \mathrm{Ba} / \mathrm{R}$, and $\mathrm{Ba} / \mathrm{Bl} / \mathrm{S}$ interacted positively with the KW12, KW13 and B10, but negatively with the KW11, KW12, B12 and B11 environments. AMMI stability values (ASV) revealed variations in grain yield stability among the 25 genotypes (cultivars and their mixtures) (Table 2). According to Purchase (1997), a stable genotype is defined as one with ASV value close to zero. Consequently, the mixtures Blask/Skarb and Basza/Blask/Rubinek with ASVs equal to 0.39 and 0.47, respectively, were the most stable while the cultivars Antek $(\mathrm{ASV}=5.88)$ and Basza $(\mathrm{ASV}=4.36)$ were the least stable (Table 2). The mixtures Blask/Skarb and Basza/Blask/ Rubinek are considered highly desirable in spring barley breeding.

Genotypes on the highest point in certain sections of the graph have the best results in environments located in the same section (Fig. 2). Mixtures A/R/S, with average grain yield (55.49 dt/ha) close to the general mean of $54.99 \mathrm{dt} / \mathrm{ha}$, is distinguished on the biplot. This mixture had the highest stability. A group of genotypes: R/S, Ba/R, Ba/S, S, Ba/Bl/S, and $\mathrm{Bl} / \mathrm{S}$ had the highest averages of yield, but with different adaptations (Figures 1 and 2): $\mathrm{R} / \mathrm{S}, \mathrm{Ba} / \mathrm{R}, \mathrm{Ba} / \mathrm{S}, \mathrm{S}, \mathrm{Ba} / \mathrm{Bl} / \mathrm{S}$ showed specific adaptation to the conditions of $\mathrm{KW} 12$ and $\mathrm{B} 10$, and $\mathrm{Bl} / \mathrm{S}$ showed general adaptation.

The difference between the mixtures and their pure cultivars in terms of the grain yield in particular environments was expressed as relevant contrast values (Table 3). Generally, the grain yield values were significantly higher in mixtures when compared with pure cultivars in all environments except Bąków 2012 and Kościelna Wieś 2012 (Table 3).

\section{Discussion}

Traditional, statistical methods (ANOVA, PCA and linear regression) are often not effective for understanding and evaluating complex data from multi-environments yield trails. More flexible statistical models for describing GEI such as the AMMI model are useful for a better understanding of GEI. The AMMI model is a hybrid analysis that incorporates both the additive and multiplicative components of the two-way data structure. AMMI biplot analysis is considered to be an effective tool to diagnose GEI patterns graphically. The additive portion is separated from interaction by analysis of variance. The principal component analysis (PCA), which provides a multiplicative model, is applied to analyze the interaction effect from the additive ANOVA model. The biplot display of PCA scores plotted against each other provides visual inspection and interpretation of GEI components. The integration of biplot display and genotypic stability statistics enables genotypes to be grouped on the basis of similarity in performance across diverse environments (Fox et al. 1997; Nowosad et al. 2016). Among the tested genotypes, the cultivar Basza had the highest IPCA 1 value of 1.74, while the highest value of IPCA 1 was 2.25 in Bąków 2013 (Fig. 1).

The clustering of some of the tested genotypes according to their IPCA 1 values and average grain yield on biplot (Figure 1) also explains their similarities in yield per plant variations (Shafii et al. 1992). In general, environments with scores near zero have little interaction across genotypes and provide low discrimination among genotypes (Anan- 
dan et al. 2009); however, in this study, this pattern was not observed in any of the locations.

A graphically represented AMMI analysis enables selection of stable and high-yielding cultivars and/or mixtures for this location, as well as genotypes with specific adaptability. The AMMI analysis is adequate in characterizing GEI for grain yield in spring barley. Abakemal et al. (2016) reached the same conclusion in their study on grain yield of 68 maize genotypes in seven environments in Ethiopia. The AMMI model was often used in study of many species (Vargas et al. 1999; Hristov et al. 2010; Zhang et al. 2013; Andrade et al. 2016). Results obtained from such analyses are very important for developing and recommending best cultivars and/or mixtures for production in a specific area, as a selection criteria for further genetic improvements and can enable objective estimation of experimental genotypes and hence developing best possible varieties for official testing by national registration authorities (Mijić et al. 2007; Nowosad et al. 2016, 2017).

\section{References}

Abakemal, D., Shimelis, H., Derera, J. 2016. Genotype-by-environment interaction and yield stability of quality protein maize hybrids developed from tropical-highland adapted inbred lines. Euphytica 209:757-769.

Anandan, A., Sabesan, T., Eswaran, R., Rajiv, G., Muthalagan, N., Suresh, R. 2009. Appraisal of environmental interaction on quality traits of rice by additive main effects and multiplicative interaction analysis. Cereal Res. Commun. 37:131-140.

Andrade, M.I., Naico, A., Ricardo, J., Eyzaguirre, R., Makunde, G.S., Ortiz, R., Grüneberg, W.J. 2016. Genotype $\times$ environment interaction and selection for drought adaptation in sweetpotato (Ipomoea batatas [L.] Lam.) in Mozambique. Euphytica 209:261-280.

Barot, S., Allard, V., Cantarel, A., Enjalbert, J., Gauffreteau, A., Goldringer, I., Lata, J., Le Roux, X., Niboyet, A., Porcher, E. 2017. Designing mixtures of varieties for multifunctional agriculture with the help of ecology. A review. Agron. Sustain. Dev. 37:13.

Elakhdar, A., Kumamaru, T., Smith, K.P., Brueggeman, R.S., Capo-Chichi, L.J.A., Solanki, S. 2017. Genotype by environment interactions (GEIs) for barley grain yield under salt stress condition. J. Crop Sci. Biotech. 20:193-204.

Finckh, M.R., Gacek, E.S., Czembor, H.J., Wolfe, M.S. 1998. Host frequency and density effects on disease and field in mixtures of barley. Plant Pathol. 48:807-816.

Fox, P.N., Crossa, J., Ramagosa, I. 1997. Multienvironment testing and genotype environment interaction. In: Kempton, R.A., Fox, P.N. (eds.), Statistical methods for plant variety evaluation. Chapman \& Hall. London, UK. pp. 117-138.

Gauch, H.G., Zobel, R.W. 1990. Imputing missing yield trial data. Theor. Appl. Genet. 79:753-761.

Gabriel, K.R. 1978. Least squares approximation of matrices by additive and multiplicative models. J. Roy. Stat. Soc. B Met. 40:186-196.

Gollob, H.F. 1968. A statistical model which combines features of factor analytic and analysis of variance techniques. Psychometrika 33:73-115.

Hristov, N., Mladenov, N., Djuric, V., Kondic-Spika, A., Marjanovic-Jeromela, A., Simic, D. 2010. Genotype by environment interactions in wheat quality breeding programs in southeast Europe. Euphytica 174:315324.

Kieloch, R., Weber, R. 2015. Influence of different herbicides on the performance of spring barley (Hordeum vulgare) cultivars in Lower Silesia region, Poland. Int. J. Agric. Biol. 17:181-186.

Mijić, A., Krizmanić, M., Liović, I., Zdunić, Z., Marić, S. 2007. Response of sunflower hybrids to growing in different environments. Cereal Res. Commun. 35:781-784. 
Nowosad, K., Liersch, A., Popławska, W., Bocianowski, J. 2016. Genotype by environment interaction for seed yield in rapeseed (Brassica napus L.) using additive main effects and multiplicative interaction model. Euphytica 208:187-194.

Nowosad, K., Liersch, A., Poplawska, W., Bocianowski, J. 2017. Genotype by environment interaction for oil content in winter oilseed rape (Brassica napus L.) using additive main effects and multiplicative interaction model. Indian J. Genet. P1. Br. 77:293-297.

Paroda, R.S., Hayes, J.D. 1971. An investigation of genotype-environment interactions for rate of ear emergence in spring barley. Heredity 26:157-175.

Philips, S.L., Wolfe, M.S. 2005. Evolutionary plant breeding for low input systems. J. Agr. Sci. 143:245-254.

Purchase, J.L. 1997. Parametric analysis to describe $\mathrm{G} \times \mathrm{E}$ interaction and yield stability in winter wheat. $\mathrm{PhD}$ Thesis, University of the Orange Free State, Bloemfontein, South Africa.

Shafii, B., Mahler, K.A., Price, W.J., Auld, D.L. 1992. Genotype $\times$ environment interaction effects on winter rapeseed yield and oil content. Crop Sci. 32:922-927.

Solonechnyi, P., Vasko, N., Naumov, A., Solonechnaya, O., Vazhenina, O., Bondareva, O., Logvinenko, Y. 2015. GGE biplot analysis of genotype by environment interaction of spring barley varieties. Zemdirbyste 102:431-436.

Vargas, W., Crossa, J., van Eeuwijk, F.A., Ramirez, E., Sayre, K. 1999. Using partial least squars regression, factorial regression and AMMI models for interpreting genotype-by-environment interaction. Crop Sci. 39:955-967.

Zhang, H., Berger, J.D., Milroy, S.P. 2013. Genotype $\times$ environment interaction studies highlight the role of phenology in specific adaptation of canola (Brassica napus) to contrasting Mediterranean climates. Field Crop. Res. 144:77-88.

Zobel, R.W., Wright, M.J., Gauch, H.G. 1988. Statistical analysis of yield trial. Agron. J. 80:388-393. 